\title{
Indian dispatch
}

\section{Background}

The foundations of rheumatology in India were laid by the late Dr M M Desai. He established the first rheumatology clinic in India at the Nair Hospital, Bombay. His enthusiasm and personality drew many physicians and orthopaedic surgeons under the banner of the Indian Rheumatism Association (IRA). The IRA is now more than 25 years old.

\section{Rheumatology centres}

Even with such an early start, rheumatology as a specialty did not really become established for a long time. Recognised rheumatology centres may now be found at Bombay, Calcutta, Chandigarh, Delhi, Lucknow, Madras, and Trivandrum; at Bombay and Delhi more than one centre exists. With the exception of one or two places, none is an independent rheumatology unit. They are manned by internists with special interest in rheumatology.

\section{Rheumatology training}

Rheumatology forms a small part of the teaching curriculum at undergraduate level. There is no formal exposure to rheumatic diseases. Even at postgraduate level things are not any better. This is mainly owing to a lack of trained and interested faculty members in the teaching institutions. As a result an average graduate or postgraduate has only a superficial view of these disorders.

There is at present only one chair of professor of rheumatology, at Madras Medical College. None of the institutions has a formal training course in rheumatology. There are no degree or diploma courses at university level. This has hampered the growth of and interest in the specialty. Efforts are being made to get rheumatology recognised by the Medical Council of India as a specialty. The few centres mentioned act as training centres for the future rheumatologists, and postgraduates from these centres have entered into practice as rheumatologists. Some have done so after securing further training in the United Kingdom or the United States. There is a need for regular established links with developed centres outside India (mainly UK, USA, Australia, and New Zealand) to provide training facilities for young aspirants. This has been the subject of discussions at SEAPAL and ILAR.
The Arthritis and Rheumatism Council (UK) has helped a few Indian trainees. The Australian rheumatism foundation has instituted a regular training fellowship. More of these are needed.

\section{Disease patterns}

For curious reasons rheumatic diseases, particularly rheumatic fever, have been wrongly thought to be uncommon in India. The same false impression holds true for other conditions. Rheumatoid arthritis, systemic lupus erythematosus, and others are quite common. There are, however, some interesting and unexplained differences. Rheumatoid arthritis is less aggressive; extra-articular manifestations are relatively uncommon. Systemic lupus erythematosus is possibly more severe, as is found in South East Asian countries and China. Osteoarthritis of the knee is common, of the hip less so. Curiously, polymyalgia rheumatica and giant cell arteritis are distinctly uncommon. The reasons for these differences are not clear, but offer important areas for future studies.

\section{Treatment}

In India for diseases like rheumatoid arthritis most patients seek alternative systems of medicine like ayurveda (the ancient Indian system of medicine) and homoeopathy, owing to the strongly prevalent notion that modern medicine has nothing to offer while the alternative systems may offer cure. This belief is prevalent in all sections of society, including the practitioners of modern medicine.

An average family doctor relies on non-steroidal anti-inflammatory drugs and corticosteroids for control of rheumatoid arthritis. Disease modifying drugs like gold and penicillamine are not used. This is partly owing (until recently) to their non-availability and partly to the fear of side effects. Cost is another deterrent. Misuse and overuse of steroids therefore becomes inevitable. To compound the problem many practitioners of indigenous systems of medicine and quacks use corticosteroids surreptitiously. Vigorous education programmes for the public and even the doctor are required. Supportive services, like physiotherapy and occupational therapy, are limited to larger institutions and cities. There is no dearth of surgeons trained in joint replacement surgery. High costs and lack of proper 
institutional facilities limit its application, however. Hip replacement is relatively common and well established. Domestic manufacture of hip prosthesis has just started.

\section{Research and drug development}

Research activities are limited to the few centres. The activity at present is mainly clinical and therapeutic. A few centres place emphasis on laboratory based studies. Paucity of funds and personnel are the main limiting factors. The central drug research institute of India has developed a few compounds - non-steroidal anti-inflammatory drugs -that are undergoing trials. A current area of study is evaluation of the drugs of the traditional systems of medicine. Interestingly, an oral gold preparation has been in use in ayurveda for a long long time. Modern medicine might study these drugs to improve its therapeutic armoury. Gugul, a plant resin, is another popular ayurvedic drug.

\section{Indian rheumatism association (IRA)}

As stated earlier, the IRA is more than 25 years old. Even so its membership is only a little over 200 . This may reflect the general apathy towards rheumatic diseases. The IRA holds an annual conference, and $\frac{0}{\infty}$ participation is steadily improving. The variety and quality of papers are also improving. Lately, 'foreign' delegates have been attending these meetings, whoo in addition to giving an international flair to the conference, have acted as a good catalyst.

The IRA brings out a bulletin, but this has had $a \oplus$ chequered existence. It is a founder member of SEAPAL, and the first SEAPAL congress was held in Bombay; IRA members have held high positions. in SEAPAL. Financial constraints have limited $\overrightarrow{\vec{H}}$ Indian participation in international conferences. $\stackrel{\omega}{\omega}$ Even so their numbers at these conferences have been increasing steadily.

This is the scenario. The future does look bright. $\stackrel{\oplus}{\infty}$ In subsequent dispatches more specific areas will be covered.

P D Hinduja National Hospital and

Medical Research Centre,

Veer Savarkar Marg,

Mahim,

Bombay 400 016, India 